OnLine Journal of Biological Sciences 8 (3): 49-56, 2008

ISSN $1608-4217$

(C) 2008 Science Publications

\title{
Induced Resistance in Mycorrhizal Tomato is correlated to Concentration of Jasmonic Acid
}

\author{
Rupam Kapoor \\ Department of Botany, University of Delhi, Delhi-110 007, India
}

\begin{abstract}
The study shows that Arbuscular Mycorrhizal Fungi (AMF) are capable of imparting disease tolerance in tomato plants pre-infected with Fusarium Oxysporum f. sp. Lycopersici (FOL). Inoculation of tomato seedlings with Glomus Macrocarpum (GM) or Glomus Fasciculatum (GF), 20 days after infection with FOL reduced pathogen spread and disease severity by 75 and $78 \%$, respectively. The mycorrhizal plants showed increased growth, possessed higher Phenylalanine Ammonia Lyase activity (PAL), phenol concentration and foliar trichome density. Upto nine-fold increase in concentration of Jasmonic Acid (JA) was observed in mycorrhizal tomato plants compared to FOL-infected control plants. The increased JA concentration in mycorrhizal plants was concomitant to systemic enhanced defence response measured in terms of increase in PAL activity, concentration of phenols and trichome density in leaves. The above parameters shoFwed strong positive correlation with endogenous level of JA. The results suggest implication of JA in AMF-induced systemic resistance.
\end{abstract}

Key words: Arbuscular mycorrhizal fungi, fusarium oxysporum f. sp. lycopersici, induced systemic resistance, jasmonic acid, phenylalanine ammonia lyase, tomato

\section{INTRODUCTION}

Arbuscular Mycorrhiza (AM) are the most common type of mycorrhizas ${ }^{[46]}$, formed between roots of more than $80 \%$ of the terrestrial plant species and fungi from the phylum Glomeromycota ${ }^{[43]}$. AM fungi provide several benefits to their host plants, including better phosphorus $(\mathrm{P})$ nutrition ${ }^{[27-30]}$, increased abiotic stress ${ }^{[19,45]}$ and increased disease resistance ${ }^{[42]}$, thus, they are widespread potential biocontrol agents. Many authors have reported that the AM symbiosis can reduce root diseases caused by several soil-borne pathogens ${ }^{[39,40]}$. However, the mechanisms underlying this protective effect are still not well understood.

The beneficial effects of the AM symbiosis result from a complex molecular dialogue between the two symbiotic partners ${ }^{[21]}$. Some processes occurring in this interaction are known to be mediated by phytohormones. Evidence for phytohormone function in establishment of AM comes mainly from application experiments ${ }^{[7,8]}$. More recent results revealed that in roots of mycorrhizal plants Jasmonic Acid (JA) levels are increased in comparison to roots of non-mycorrhizal controls $^{[37,47,50]}$. Though several reports suggest improved Phosphorus (P) uptake, competition for space and nutrients, mycorrhizosphere effect and activation of defence mechanism responsible for disease inhibition by AMF; there have been a very few studies implicating jasmonic acid in enhanced disease resistance in mycorrhizal plants.

The present study shows the potential of Glomus macrocarpum and Glomus fasciculatum in control of Fusarium Oxysporum f. sp. Lycopersici (FOL) causing wilt in tomato. The experiment was carried out to elucidate the role of jasmonic acid in enhanced defense response of mycorrhizal plants; and to know if any correlation exists between endogenous level of jasmonic acid and markers of enhanced defense such as phenylalanine ammonia lyase activity, phenol concentration and trichome density in mycorrhizal plants.

\section{MATERIALS AND METHODS}

Plant material: Seeds of lycopersicon esculentum var. Pusa Bharti were obtained from national seed cooperation, Indian Agricultural Research Institute (IARI), New Delhi. The cultivar is moderately resistant to the Fusarium Oxysporum f. sp. Lycopersici (FOL) race procured.

Pathogen cultures: A pathogenic isolate of Fusarium oxysporum $^{[25]}$ f. sp. lycopersici was obtained from division of plant pathology, Indian Agricultural Research Institute (IARI), India and maintained on 
Potato Dextrose Agar (PDA). Conidial suspension was prepared and spore density was determined using haemocytometer to be $2.8 \times 10^{6}$ spores $\mathrm{Ml}^{-1}$.

Arbuscular mycorrhizal inoculum: Soil based inocula of Glomus fasciculatum (Thaxter sensu Gerd.) Gerdemann and Trappe and Glomus macrocarpum Tul. and Tul. were multiplied using Sorghum halepense as trap plant ${ }^{[27]}$. The inoculum density for both AMF species was found to be $96-98$ spores per $10 \mathrm{~g}$ soil.

Experimental design: The investigation consisted of pot experiment, carried out at the Botanical Garden, Department of Botany, University of Delhi. Seeds of tomato were germinated on steam sterilized soil (15 lbs, 20 min.). Ten days after germination, seedlings were challenged with pathogen (Fusarium oxysporum f. sp. lycopersici) by injecting conidial suspension near the roots at the rate of $10 \mathrm{~mL}^{-1}$ seedling. One month old, seedlings were transplanted to earthenware pots filled with a mixture of sand and soil $(1: 1, \mathrm{v} / \mathrm{v})$. Before dispensing into pots the sand and soil mixture was sterilized by fumigation $(0.1 \%$ formaldehyde $)$. Experiment was designed in randomized block consisted of three different mycorrhizal treatments, viz. non-mycorrhizal, inoculated with Glomus macrocarpum or inoculated with Glomus fasciculatum, each with three plants per pot in six replicates (total 18 plants for each treatment). A soil based inoculum (10 g per pot) including root fragments ( $88 \%$ colonized), was added to each pot at the time of transplanting just below the tomato seedlings. Soil treatment with FOL to plants not given any mycorrhizal inoculation served as the control. Plants were grown under natural conditions of light, temperature and relative humidity. Plants were watered regularly and no pesticides or fertilizers were applied.

Evaluation of disease incidence: Disease incidence was visually estimated during the growth period following challenged inoculation with FOL. The rating scale was $0 \%$ (no diseased plants) to $100 \%$ (all plants diseased). Each diseased plant had typical tomato wilt symptoms $^{[1]}$.

Measurement of the tomato plants: After 51 days three plants from each treatment were harvested along with the roots and the dry weights of shoot and root were recorded after drying them in an oven at 70-80 ${ }^{\circ} \mathrm{C}$ for two days till their weight was constant.

Estimation of proteins: Freshly harvested plant material was homogenized in $0.1 \mathrm{M}$ Phosphate buffer (pH 7.2), filtered and centrifuged at $9000 \mathrm{rpm}$ for 10 min at $4{ }^{\circ} \mathrm{C}$. The supernatant was mixed with equal volume of $10 \%$ tri-chloro acetic acid and again centrifuged at $3300 \mathrm{rpm}$ for $10 \mathrm{~min}$ at $4{ }^{\circ} \mathrm{C}$. The pellet was washed with water 2-3 times and then dissolved in $0.1 \mathrm{~N} \mathrm{NaOH}$. Proteins were quantified by the protein dye binding method of Bradford (1976) using Bovine Serum Albumin (BSA) as a standard.

\section{Estimation of total phenols and O-dihydric phenols:} The estimation of total phenols and Ortho-dihydric phenols were assayed according to Bray and Thorpe and Johnson and Schaal ${ }^{[10,26]}$, respectively. Freshly harvested leaves were homogenized in ethanol and the supernatant was mixed with Folin-Ciocalteu's phenol Reagent (FCR). The intensity of the blue colour was read at $650 \mathrm{~nm}$.

For O-dihydric phenol, the supernatant was mixed with $0.05 \mathrm{~N} \mathrm{HCl}$, Arnow's reagent, and $1 \mathrm{~N} \mathrm{NaOH}$. The absorbance was read at $515 \mathrm{~nm}$. Standard curve was prepared using pyro-catechol.

Estimation of phenylalanine ammonia lyase activity (EC 4.1.1.5): Phenylalanine Ammonia Lyase (PAL) activity was assayed according to Dunn et al. ${ }^{[17]}$ with slight modifications. Frozen shoot ( $1 \mathrm{~g})$ were homogenized in $10 \mathrm{ml} 0.1 \mathrm{M}$ sodium borate buffer, $\mathrm{pH}$ 8.8 containing $10 \mathrm{mM} \beta$-mercaptoethanol and $10 \%$ (w/w) Polyvinyl Pyrroprolidine (PVPP). Crude extracts were centrifuged at $12,000 \mathrm{rpm}$ for $20 \mathrm{~min}$ at $4{ }^{\circ} \mathrm{C}$. Reaction mixtures containing $750 \mu$ l enzyme extract, $1.25 \mathrm{~mL}$ sodium borate buffer and $500 \mu \mathrm{l}$ sodium borate buffer plus $0.05 \mathrm{~mL}$-phenylalanine were incubated in a water bath at $40{ }^{\circ} \mathrm{C}$ for $3 \mathrm{~h}$. Absorbance was taken at $290 \mathrm{~nm}$.

Extraction and purification of jasmonic acid: Four month old, foliar tissue was harvested and the plant material was ground into a fine powder under liquid nitrogen and $10 \mathrm{~g}$ fresh weight samples were taken for further analysis. For purification ${ }^{[18]}$, samples were applied to open columns of octadecyl silica (C-18, 3-4 $\mathrm{mL}$ bed volume,). The C-18 columns were preequilibrated in $100 \%$ methanol, followed by $1 \%$ acetic acid (10 column volumes of each). The sample was then loaded and washed through with $15 \mathrm{~mL} 1 \%$ acetic acid, $15 \mathrm{~mL} 1 \%$ acetic acid in $30 \%$ aqueous methanol and $30 \mathrm{~mL} 1 \%$ acetic acid in $60 \%$ aqueous methanol. Jasmonic acid in the $60 \%$ methanol wash was collected. The eluent was then dried completely, and subsequently resuspended in $70 \mu \mathrm{l}$ solvent $(0.05 \%$ trifluoroacetic acid (TFA) in $40 \%$ aqueous acetonitrile, $\mathrm{MeCN}$ ) prior to injection onto HPLC instrument (Schimadzu CLASS-VP V 6.13 SPI HPLC). 
OnLine J. Biol. Sci., 8 (3): 49-56, 2008

Table 1: Effects of colonization by AM fungi on biomass, phosphorus concentration, protein and total phenol concentration in root and shoot of tomato plants infected with Fusarium oxysporum f. sp. lycopersici.

\begin{tabular}{|c|c|c|c|c|c|c|c|c|}
\hline \multirow[t]{2}{*}{ Treatments } & \multicolumn{2}{|c|}{ Biomass (g) } & \multicolumn{2}{|c|}{ Phosphorus concentration (\%) } & \multicolumn{2}{|c|}{ Protein concentration $\left(\mathrm{mg} \mathrm{g}^{-1}\right)$} & \multicolumn{2}{|c|}{ Total phenol concentration $\left(\mathrm{mm} \mathrm{g}^{-1}\right)$} \\
\hline & Root & Shoot & Root & Shoot & Root & Shoot & Root & Shoot \\
\hline Control & $0.33 \mathrm{a}$ & $3.09 \mathrm{a}$ & $0.82 \mathrm{a}$ & $0.73 \mathrm{a}$ & $1.66 \mathrm{a}$ & $58.0 \mathrm{a}$ & $4.33 \mathrm{a}$ & $10.66 \mathrm{a}$ \\
\hline $\mathrm{C}+\mathrm{GM}$ & $0.36 \mathrm{~b}$ & $3.98 \mathrm{c}$ & $2.36 \mathrm{~b}$ & $2.03 \mathrm{c}$ & $3.66 \mathrm{~b}$ & $64.0 \mathrm{~b}$ & $8.00 \mathrm{~b}$ & $21.00 \mathrm{~b}$ \\
\hline $\mathrm{C}+\mathrm{GF}$ & $0.35 \mathrm{~b}$ & $3.27 \mathrm{~b}$ & $2.92 \mathrm{c}$ & $2.00 \mathrm{~b}$ & $3.66 \mathrm{~b}$ & $61.0 \mathrm{ab}$ & $5.00 \mathrm{a}$ & $16.33 \mathrm{~b}$ \\
\hline
\end{tabular}

Values are mean of three replicates. Within a column; values followed by the same letters are not significantly different $(\mathrm{P}=0.05)$ by Tuckey post hoc test using Statistical Package for Social Sciences (SPSS) software. C - control, GM - Glomus Macrocarpum, GF - Glomus Fasciculatum

HPLC separation of jasmonic acid: Separation of jasmonic acid was achieved using reverse phase HPLC on an octadecyl silica C-18 column, using solvent at the flow rate of $1 \mathrm{~mL} \mathrm{~min}{ }^{-1}$. The solvent gradient was followed as mentioned in Gapper et al. $2002^{[18]}$. The separation of jasmonic acid was verified using standards from Sigma-Aldrich, India and expressed in nmol g${ }^{-1}$ fresh weight shoot.

Measurement of trichome density: Trichome density was measured according to ${ }^{[33]}$ from the upper leaf surface. The leaf discs (area- $0.29 \mathrm{~cm}^{2}$ ) were taken from the center of the leaf blade and counted for adaxial trichome number under a compound light microscope. Trichome density was calculated as the trichome number per disc area.

Concentration of phosphorus: Dried samples were ground, digested in concentrated acid $\left(\mathrm{HNO}_{3}: \mathrm{HClO}_{4}\right.$, $2: 3, \mathrm{v} / \mathrm{v}$ ) at $140-160{ }^{\circ} \mathrm{C}$. After cooling, the extracts were diluted with $1 \mathrm{~N} \mathrm{HCl}$ and made up to $25 \mathrm{~mL}^{[3]}$. Reagent blanks were prepared by carrying out the whole extraction procedure but in the absence of sample. The phosphorus in the digested sample was estimated by molybdenum blue method ${ }^{[3]}$ at $700 \mathrm{~nm}$ using UV spectrophotometer. Working standards were procured from Sigma-Aldrich, U.S.A.

Statistical analysis: One-way analysis of variance was carried out for each parameter studied. Tukey's post hoc multiple mean comparison test was used to test for significant differences between treatments (at 5\% level). All statistical analyses were performed with Statistical Package for Social Sciences version 10 (SPSS Inc., Wacker Drive, Chicago, IL).

\section{RESULTS}

Tomato plants infected with Fusarium oxysporum f. sp. lycopersici showed symptoms of vascular wilt, formation of yellow patches and wilting after 21 days of inoculation of the pathogen. The two Arbuscular
Mycorrhizal Fungi (AMF) were able to colonize tomato roots infected with Fusarium Oxysporum f. sp. Lycopersici (FOL). The per cent colonization was observed to be 76.66 and $63.66 \%$ for GM and GF, respectively. Treatment of tomato plants with AMF i.e., Glomus macrocarpum or Glomus fasciculatum (20 days after inoculation with FOL) reduced pathogen spread and disease by 75 and $78 \%$ respectively.

Mycorrhizal colonization enhanced growth of tomato plants. Root and shoot biomass of mycorrhizal plants was significantly higher than control plants (Table 1). The mycorrhizal plants also possessed significantly higher concentration of phosphorus both in root as well as shoot in comparison to control plants (Table 1).

Roots colonized by G. macrocarpum or G. fasciculatum showed about 3-fold increase in concentration of proteins (Table 1). Protein concentration in shoot was significantly higher in GM plants; however the increase in shoot protein in GF plants over control was not statistically significant.

Plants inoculated with GM showed upto 2-times concentration of total phenols in root as well as shoot over control (Table 1), in GF inoculated plants, the increase was not significant in roots. Also, 2-fold increase in concentration of O-dihydric phenol in GM colonized shoots was observed as compared to control plants (Fig. 1a).

AM colonization of FOL infected plants induced up to 6-fold phenylalanine ammonia lyase activity over their non-mycorrhizal control (Fig. 1b). Highest PAL activity was measured in GM inoculated plants.

Microscopic observations of tomato leaf discs showed increase in the trichome density. Maximum trichome production was observed in $\mathrm{C}+\mathrm{GF}$ treatment (Fig. 1c). The two mycorrhizal treatments were comparable in terms of trichome density.

Jasmonic Acid (JA) level in control tomato plants were $0.49 \mathrm{nM} \mathrm{g}^{-1}$ fresh weight (Fig. 2). Mycorrhization led to remarkable increase in concentration of JA (9.3 $\mathrm{nM} \mathrm{g}^{-1}$ fresh weight). Markers of defensive capacity of plants i.e. trichome density, PAL activity and phenol 
OnLine J. Biol. Sci., 8 (3): 49-56, 2008
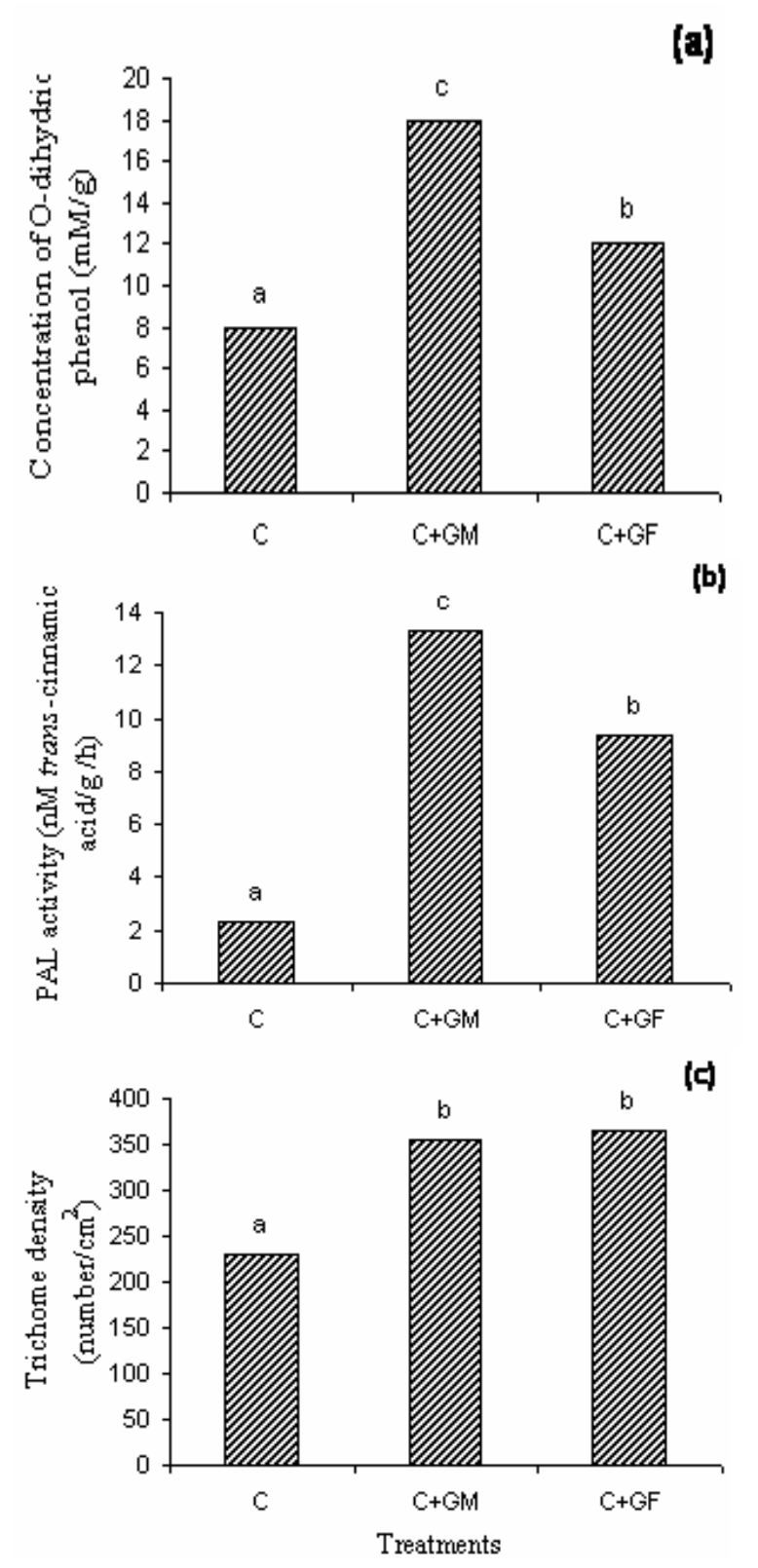

Fig. 1: Effects of colonization by AM fungi on the concentration of O-dihydric phenol (a), phenylalanine ammonia lyase activity (b) and foliar trichome density (c) in shoot of Lycopersicon esculentum plants infected with Fusarium oxysporum f. sp. lycopersici. Ccontrol, GM-Glomus macrocarpum, GFGlomus fasciculatum. Values are mean of three replicates. Histograms with the different letter are significantly different a $\mathrm{p} \leq 0.05$ by SPSS (statistical package for social sciences software), Tukey, Post hoc test

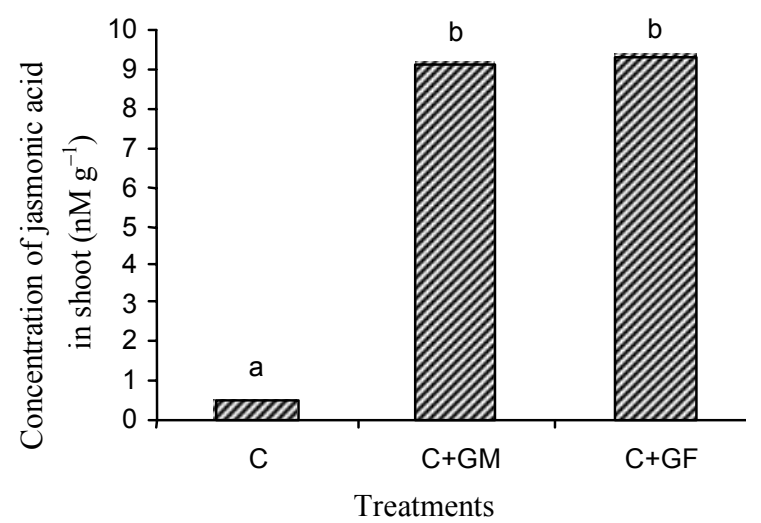

Fig. 2: Effects of colonization by AM fungi on the concentration of jasmonic acid in shoot of Lycopersicon esculentum plants infected with Fusarium oxysporum f. sp. lycopersici. Ccontrol, GM-Glomus macrocarpum, GF Glomus fasciculatum. Values are mean of three replicates. Histograms with the different letter are significantly different a $\mathrm{p} \leq 0.05$ by SPSS (statistical package for social sciences software), Tukey, Post hoc test

concentration showed high positive correlation with endogenous concentration of JA, i.e., $r^{2}=0.997, r^{2}=$ 0.927 and $\mathrm{r}^{2}=0.885$ (Fig. 3a, b, c) respectively.

\section{DISCUSSION}

There have been several reports on increased disease tolerance of plants to soil-borne pathogens on pre-inoculation with mycorrhizal fungi $i^{[4,6,13]}$. This study reports effectiveness of mycorrhizal fungi to control vascular wilt disease, after the establishment of the pathogen. GM and GF were successful in colonizing the tomato roots infected with FOL.

Mycorrhizal colonization resulted in increased growth and enhanced Phosphorus (P)-concentration over non-mycorrhizal plants. In earlier studies, the disease inhibition by AMF has been linked to their ameliorative effects for plant nutrients especially for $\mathrm{P}$ concentration $^{[11,41]}$. Later, some researchers presumed that the disease inhibition by AMF might not be completely related to the increase in P-content and dry weight $^{[2]}$. It has been thought that besides the plant nutrient uptake, the competition for space and nutrients, mycorrhizosphere effect ${ }^{[31]}$ and activation of plant defence mechanisms is responsible for disease inhibition by $\mathrm{AMF}^{[2,4,27]}$. Pre-infection of $\mathrm{FOL}$ over mycorrhizal fungi in this study imparted temporal 

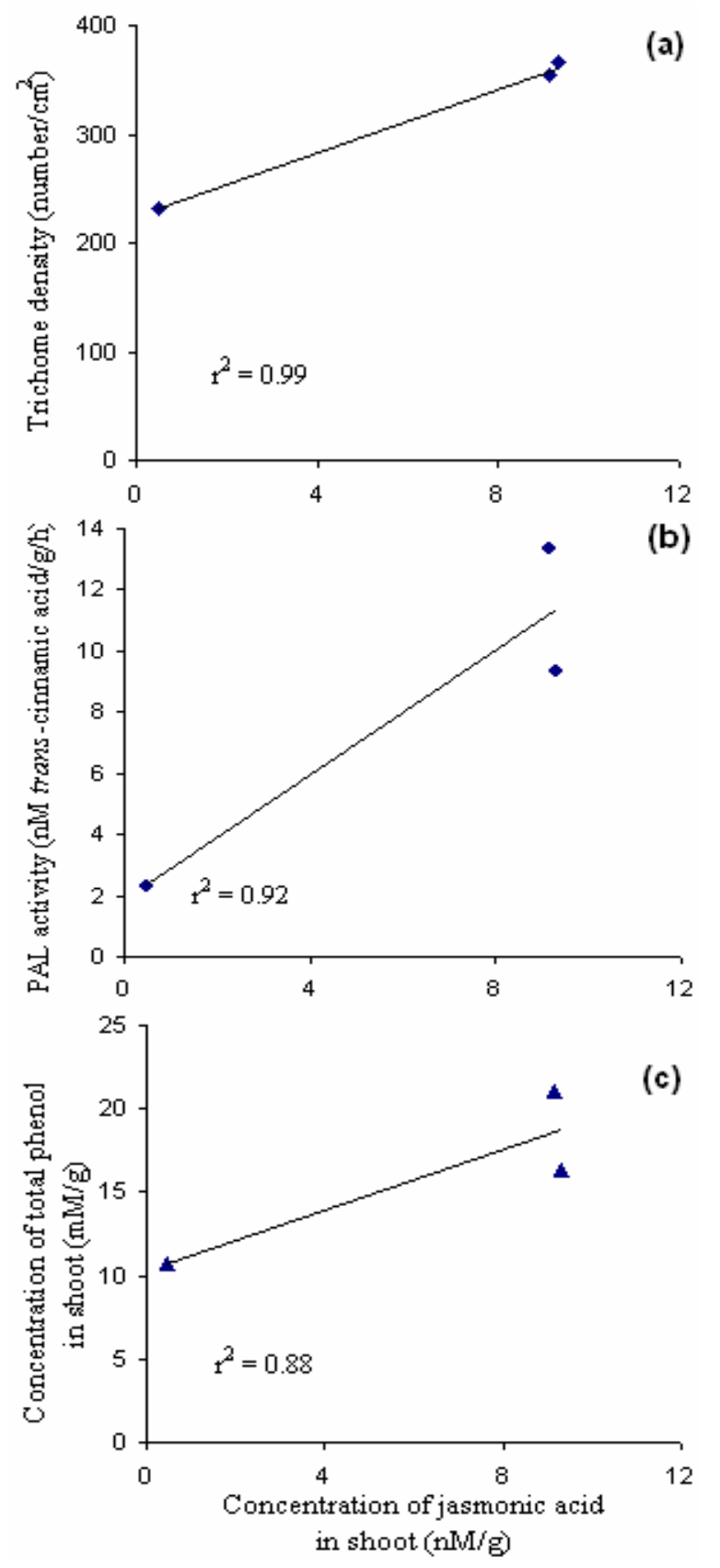

Fig. 3: Relationship between the concentration of jasmonic acid with trichome density (a), phenylalanine ammonia lyase activity (b) and concentration of total phenols (c) in shoot of Lycopersicon esculentum infected with Fusarium oxysporum f. sp. lycopersici

advantage to the pathogen and relieved it of space competition during initial stages of infection. Therefore, decreased disease incidence due to competition for space and infection sites may be ruled out in this study.

Mycorrhization resulted in increase in the density of trichomes on leaves. This observation is in accordance with the observation of Copetta et al. and Kapoor et al., ${ }^{[12,27]}$. Trichomes are important structural barrier component of resistance and glandular trichomes are sites for accumulation of secondary metabolites ${ }^{[48]}$. Increase in foliar tissue density indicates induction of systemic resistance in mycorrhizal plants. Phenylalanine Ammonia Lyase (PAL) is involved in the flow of carbon from primary to secondary metabolites in plants ${ }^{[20]}$. PAL is the first enzyme in the phenylpropanoid pathway, leading to the conversion of L-phenylalanine into trans-cinnamic acid $^{[15]}$ which leads to production of phytoalexins and phenolic substances. Colonization of roots by AMF stimulates the phenylpropanoid pathway ${ }^{[38]}$, it may be due to the induction of PAL activity as observed in the present study.

The role of phenols in suppressing pathogens has been extensively discussed by various researchers. Increased phenol concentration in plant tissue following pathogen attack is one of the important mechanism, by which pathogen activity may be limited, or decreased $^{[44]}$. In the present study, the effect of mycorrhiza induced increase in phenol concentration in the plant tissue. The results are in accordance with those of Mathur and Vyas ${ }^{[36]}$. Devi and Reddy ${ }^{[16]}$ revealed that inoculation with G. mosseae induced not only quantitative but also qualitative changes in phenolic acids in groundnut plant tissue. Although these results have not been correlated to the inhibition of the pathogen, current experiment indicated that the increase in phenol concentration can contribute to the inhibitory effect on the pathogen. Increased phenols locally induced by AM fungi were reported for some plant, but the literature on increased phenols systemically induced by AM fungi is still scarce. Cordier et al ${ }^{[14]}$ found that decreased colonization by Phythophthora parasitica in mycorrhizal and non-mycorrhizal parts of mycorrhizal plants was associated with an accumulation of phenolics. Ortho-dihydric phenol level was also found to be increased in mycorrhizal plants. Increased levels of Ortho-dihydric phenols in mycorrhizal plants have also been argued to impart disease resistance ${ }^{[32]}$. Increase in concentration of phenols and O-dihydric phenols in mycorrhizal tomato plants may be due to induction of PAL enzyme activity as discussed earlier.

Jasmonic acid concentrations were nine times higher in mycorrhizal plants than in non-mycorrhizal shoots, similar level of increase have been reported in 
mycorrhizal barley ${ }^{[22]}$ and Medicago trucatula ${ }^{[47]}$. JA may be a systemic signal and dislocated throughout the plant ${ }^{[34]}$. Increase in levels of endogenous jasmonates are followed by activation of genes involved in plant defence responses such as those coding for enzymes of phytoalexins synthesis, vegetative storage proteins ${ }^{[23,35]}$.

Studies have shown that increase in endogenous level of jasmonic acid results in induction of trichomes $^{[49]}$ and present results confirm such reports where a strong positive correlation was observed between trichome density of leaves and endogenous level of jasmonic acid. Present results therefore provide evidence that AMF regulate systemic increase in physical defence in tomato by increasing the concentration of JA. According to Traw and Bergelson the effect of jasmonic acid reflected on increase in proportion of cells that become trichomes, rather than in increase in the overall epidermal cell number of the leaves ${ }^{[49]}$.

We observed positive correlation between PAL activity and JA, which suggests that increase in AMF induced PAL activity may be mediated through increased levels of JA on mycorrhization.

The results indicate that AMF impart induced systemic resistance in host plants. This may be due to systemic increase in concentration of jasmonic acid resulting in increase in trichome density, higher protein concentration, induction of PAL activity and accumulation of phenols.

\section{ACKNOWLEDGEMENTS}

We are thankful to Division of Plant Pathology, Indian Agricultural Research Institute (IARI), India for providing pure culture of Fusarium oxysporum f. sp. lycopersici. We thank Mustard Research and Promotion Consortium (MRPC), New Delhi, India for providing the facility for High Performance Liquid Chromatography. Financial support by University of Delhi is gratefully acknowledged

\section{REFERENCES}

1. Agrios, G.N., 1997. Plant Pathology. 4th Edn., Academic Press, New York, U.S.A.

2. Akkapru, A. and S. Demir, 2005. Biological control of fusarium wilt in tomato caused by fusarium oxysporum f. sp. lycopersici by AMF glomus intraradices and some rhizobacteria. J. Phytopathol., 153: 544-550.

3. Allen, S.E., 1989. Chemical Analysis of Ecological Materials. Blackwell, London.
4. Azcon-Aguilar, C., J.M. Barea, 1996. Arbuscular mycorrhizas and biological control of soil-borne plant pathogens-an overview of the mechanisms involved. Mycorrhiza, 6: 457-464.

6. Barea, J.M. and P. Jefferies, 1995. Arbuscular Mycorrhizas in Sustainable Soil Plant Systems. In: Mycorrhiza Structure, Function, Molecular Biology and Biotechnology, Hock, B. and A. Varma, (Eds.). Springer, Heidelberg, pp: 521-559.

7. Barker, S. and D. Tagu, 2000. The roles of auxins and cytokinins in mycorrhizal symbiosis. J. Plant Growth Regul., 19: 144-154.

8. Bothe, H., A. Klingner, M. Kaldorf, O. Schimtz, H. Esch, B. Hundeshagen and H. Kernebeck, 1994. Biochemical approaches to the study of plantfungal interactions in arbuscular mycorrhiza. Experimentia, 50: 919-925.

9. Bradford, M.M., 1976. A rapid and sensitive method for the quantification of microgram quantities of protein utilizing the principle of protein dye binding. Anal. Biochem., 72: 248-254.

10. Bray, H.G. and W.V. Thorpe, 1954. Analysis of phenolic compounds of interest in metabolism. Method Biochem. Anal., 1: 27-52.

11. Caron, M., J.A. Fortini, C. Richard, 1986. Effect of phosphorus concentration and glomus intraradices on fusarium crown and root rot of tomatoes. Phytopathology, 76: 942-946.

12. Copetta, A., G. Lingua and G. Berta, 2006. Effects of three AM fungi on growth, distribution of glandular hairs and essential oil production in ocimum basilicum. Mycorrhiza, 16: 485-494.

13. Cordier, C., S. Gianinazzi and V. GianinazziPearson, 1996. Colonization patterns of root tissues by phytophthora nicotianae var. parasitica related to reduced disease in mycorrhizal tomato. Plant soil, 185: 223-232.

14. Cordier, C., M.J. Pozo, J.M. Barea, S. Gianinazzi and V. Gianinazzi-Pearson, 1998. Cell defense responses associated with localized and systemic resistance to phytophthora parasitica induced in tomato by an arbuscular mycorrhizal fungus. Mol. Plant Microbe. Interact., 11: 1017-1028.

15. Da Cuhna, A., 1987. The establishment of L-phenylalanine ammonia lyase shows phenylpropanoid biosynthesis to be regulated by L-phenylalanine supply and availablility. Phytochemistry, 26: 2723-2727.

16. Devi, M.C. and M.N. Reddy, 2002. Phenolic acid metabolism of groundnut (Arachis hypogaea L.) plants inoculation with VAM fungus and rhizobium. Plant Growth Regulat., 37: 151-156. 
17. Dunn, D.C., L.W. Duncan and J.T. Romeo, 1998. Changes in arginine, PAL activity and nematode behavior in salinity stressed citrus. Phytochemistry, 49: 413-417.

18. Gapper, G., E. Nigel, S.F. Norris, R.E. Clarke and P.E. Jameson, 2002. Asparagus officinalis during harvest induced and natural foliar senescence. Physiol. Plantarum, 114: 116-124.

19. Giri, B., R. Kapoor and K.G. Mukerji, 2003. Influence of arbuscular mycorrhizal fungi and salinity on growth, biomass and mineral nutrition of Acacia auriculiformis. Biol. Fertil. Soils 38: 170-175.

20. Hahlbrock, K. and D. Scheel, 1989. Physiology and molecular biology of phenylpropanoid metabolism. Ann. Rev. Plant Physiol. Plant Mol. Biol., 40: 347-369.

21. Harrison, M., 1999. Molecular and cellular aspects of the arbuscular mycorrhizal symbiosis. Ann. Rev. Plant Physiol. Plant Mol. Biol., 50: 361-389, DOI: 10.1146/annurev.arplant.50.1.

22. Hause, B., W. Maler, O. Meirsch, R. Kramell and D. Strack, 2002. Induction of jasmonate biosysnthesis in arbuscular mycorrhizal barley roots. Plant Physiol., 130: 1213-1220.

23. Hause, B., C. Mrosk and D. Strack, 2007. Jasmonates in arbuscular mycorrhizal interactions. Phyochemistry, 68: 101-110, DOI: 10.1016/j.phytochem.2006.09.025.

24. Hooker, J.E., M. Jaizme-Vega and D. Atkinson, 1994. Biocontrol of Plant Pathogens using Arbuscular Mycorrhizal Fungi. In: Impact of Arbuscular Mycorrhizas on Sustainable Agriculture and Natural Ecosystems, Gianinazzi, S. and H. Schuepp, (Eds.). Birkhauser, Basel, pp: 191-200.

25. Jarvis, W.R., 1998. Fusarium crown and root rot of tomatoes. Phytoprotection, 69: 49-64.

26. Johnson, G. and L.A. Schaal, 1957. Chlorogenic acid and ortho-dihyroxy phenols in scab resistant Russet burbank and scab susceptible triumph potato tubers of different maturities. Phytopathology, 47: 253-258.

27. Kapoor, R., V. Chaudhary and A.K. Bhatnagar, 2007. Effects of arbuscular mycorrhiza and phosphorus application on artemisinin concentration in artemisia annиa L. Mycorrhiza, 17: 581-587.

28. Kapoor, R., B. Giri and K.G. Mukerji, 2004. Improved growth and essential oil yield and quality in Foeniculum vulgare Mill. on mycorrhizal inoculation supplemented with P-fertilizer. Bioresour. Technol., 93: 307-311.
29. Kapoor, R., B. Giri and K.G. Mukerji, 2002. Glomus macrocarpum: A potential bioinoculant to improve essential oil quality and concentration in dill (anethum graveolens L.) and carum (trachyspermum ammi Linn.) sprague). World J. Microbiol. Biotechnol., 18: 459-463.

30. Kapoor, R., B. Giri and K.G. Mukerji, 2002 b. Mycorrhization of coriander (coriandrum sativum $L$.) to enhance the concentration and quality of essential oil. J. Sci. Food Agric., 88: 1-4.

31. Kapoor, R. and K.G. Mukerji, 1998. Microbial interactions in mycorrhizosphere of anethum graveolens L. Phytomorphology, 48: 383-389.

32. Krishna, K.R. and D.J. Bagyaraj, 1984. Phenols in mycorrhizal root of arachis hypogea. Experimentia, 40: 85-86.

33. Larkin, J.C., N. Young, M. Prigge and M.D. Marks, 1996. The control of trichome spacing and number in arabidopsis. Development, 122: 997-1005.

34. Li, L., C. Li, G.I. Lee and G.A. Howe, 2002. Distinct roles for jasmonate synthesis and action in the systemic wound response of tomato. Proc. Natl. Acad. Sci., 99: 6416-6421.

35. Lorenzo, O., R. Solano, 2005. Molecular players regulating the jasmonate signaling network. Plant Biol., 8: 532-540.

36. Mathur, N. and A. Vyas, 1996. Relative efficiency of different VAM fungi on growth and nutrient uptake in ziziphyus mauritiana. Indian J. Fores, 19: 129-131.

37. Meixner, C., J. Ludwig-Muller, O. Meirsch, P. Gresshoff, C. Staehelin and H. Vierheilig, 2005. Lack of mycorrhizal autoregualtion and phytohormonal changes in the super-nodulating soybean mutant nts 1007. Planta, 222: 709-715.

38. Morandi, D., 1996. Occurrence of phytoalexins and phenolic compounds in endomycorrhizal interactions and their potential role in biological control. Plant Soil, 185: 241-251.

39. Murphy, J.F., G.W. Zehnder, D.J. Schuster, E.J. Sikora, J.E. Polston and J.W. Kloepper, 2000. Plant growth-promoting rhizobacteria mediated protection in tomato against tomato mottle virus. Plant Dis., 84: 779-784.

40. Norman, J.R. and J.E. Hooker, 2000. Sporulation of Phytophthora fragariae shows greater stimulation by exudates of non-mycorrhizal than by mycorrhizal strawberry roots. Mycol. Res., 104: 1069-1073.

41. Ozgonen, H., M. Bicini and A. Erkihc, 1999. The effect of salicylic acid and endomycorrhizal fungus glomus etunicatum on plant development of tomatoes and fusarium wilt caused by fusarium oxysporum f. sp. lycopersici. Turk J. Agric., 25: 25-29. 
42. Pozo, M.J., C. Azcón-Aguilar, E. Dumas-Gaudot and J.M. Barea, 1999. $\beta$-1-3 glucanase activities in tomato root inoculated with the arbuscular mycorrhizal fungi and/or phytophthora parasitica and their possible involvement in bioprotection. Plant Sci., 14: 149-157.

43. Schussler, A., D. Schwarzott, C. Walker, 2001. A new fungal phylum, the glomeromycota: Phylogeny and evolution. Mycol., Res., 105: 14131421.

44. Sedlarova, M., P. Binarova and A. Lebeda, 2001. Changes in microtubular alignement in lactuca spp. (asteraceae) epidermal cells during early stages of infection by bremia lactucae (peronosporaceae). Phyton., 41: 21-34

45. Sharma, D., R. Kapoor and A.K. Bhatnagar, 2008 AM fungi help in conservation of curculigo orchioides gaertn-a vulnerable anticancerous plant. World J. Microbiol. Biotechnol., 24: 395-400.

46. Smith, S.E. and D.J. Read, 1997. Mycorrhizal Symbiosis. Academic Press, London
47. Stumpe, M., J.G. Carsjens, I. Stenzel, G. Cornelia, I. Lang, K. Pawlowski, B. Hause and I. Feussner, 2005. Lipid metabolism in arbuscular mycorrhizal roots of medicago truncatula. Phytochemistry, 66: 781-791.

48. Traw, M.B. and T.E. Dawson, 2002. Differential induction of trichomes by three herbivores of black mustard. Oecologia, 131: 526-532.

49. Traw, M.B., J. Kim, S. Enright, D.F. Cipollini and J. Bergelson, 2003. Negative cross-talk between salicylate and jasmonate-mediated pathways in the wassilewskija ecotype of arabidopsis thaliana. Mol. Ecol., 12: 1125-1135.

50. Vierheilig, H. and Y. Piche, 2002. Signalling in Arbuscular Mycorrhiza: Facts and Hypothesis. In: Flavanoids in Cell Function, Busling, B. and J. Manthey, (Eds.). Kluwer Academic Publishers/Plenum Press, New York, pp: 209, ISBN: 0306472546, 9780306472541. 